\title{
Perancangan Permukiman pada Lahan Terbatas
}

\author{
Anggun Fresiani dan Muhammad Faqih \\ Departemen Arsitektur Desain dan Perencanaan Institut Teknologi Sepuluh Nopember (ITS) \\ e-mail: faqih@arch.its.ac.id
}

\begin{abstract}
Abstrak-Kota yang inklusif merupakan kota dengan segala macam yang ada di dalamnya dapat dijangkau dan dinikmati seluruh lapisan masyarakat. Hal tersebut menjadi penting karena fasilitas kota seharusnya dapat dirasakan oleh segala golongan. Namun faktanya, mengenai inklusifitas masih harus diciptakan di banyak bidang, salah satunya mengenai permukiman yang berada di bantaran rel kereta api Sidotopo. Penelitian yang merupakan bagian dari penyelesaian masalah ini mengacu pada tujuan SGDs nomor 11 yang mengusung tentang kota dan hunian inklusif. Masalah yang muncul utamanya mengenai lahan terbatas, privasi, kebutuhan ruang dan pemenuhan lingkungan sehat. Di dalamnya, terdapat lima tahapan design framework dengan menggunakan pendekatan perilaku. Pattern-based design method digunakan sebagai alat eksplorasi desain untuk mencapai efektivitas dalam penerapan pada hunian dan lingkungan yang inklusif. Tujuan dari perancangan ini yaitu untuk mewujudkan permukiman inklusif yang dapat mewadahi fasilitas dan kebutuhan, baik ruang maupun fisik pada lahan terbatas untuk kalangan masyarakat yang tidak dapat menjangkau secara individu. Dengan masalah dan tujuan tersebut, penyelesaian yang dihasilkan yaitu terpenuhinya standar fasilitas lingkungan hunian dengan efisiensinya; terakomodasinya program aktivitas pada ruang hunian, dengan terbentuknya empat tipe hunian yang ukuran luasannya berbeda pada setiap tipe.
\end{abstract}

Kata Kunci-Inklusif, Hunian, Lahan Terbatas, Fasilitas Kota.

\section{PENDAHULUAN}

$\mathrm{F}$ ASILITAS kota, pada prinsipnya merupakan banyak hal yang dapat dinikmati dan didapatkan oleh setiap masyarakat di dalamnya. Terdapat berbagai macam jenis fasilitas, misalnya bangunan publik, hal khusus untuk pengguna disabilitas, hak ruang dan kondisi untuk anak-anak, hak kebutuhan dasar setiap individu, hak tinggal dalam kota dengan keamanan dan kenyamanannya, dan hal-hal lain yang menunjang berkehidupan melalui fasilitas yang disediakan.

Namum faktanya fasilitas yang seharusnya dapat dijangkau seluruh lapisan masyarakat masih bertahan pada beberapa golongan yang dapat menikmati. Sebagian lainnya tidak dapat menjangkau atau bahkan belum tersedia. Sebagai contoh bangunan publik yang belum memudahkan semua jenis pengguna; hak runag untuk anak-anak, meskipun beberapa dapat dimonopoli oleh sebagian pihak untuk menyediakan ruang bagi anak-anak, namun penyediaannya tidak dapat dinikmati semua anak-anak. Jika dilihat lebih luas, inklusifitas yang bertahan lama belum terwujud yaitu pada bidang kelayakan berhuni terutama di kota.-kota besar. Banyak mereka yang tinggal di dalamnya tidak mendapat dan menikmati sebagian besar unsur kota bahkan seluruhnya.

Fasilitas kota, suatu hal yang akan bisa menjadi sangat dekat dan bisa menjadi sangat jauh, bagi masyarakat pemiliknya.

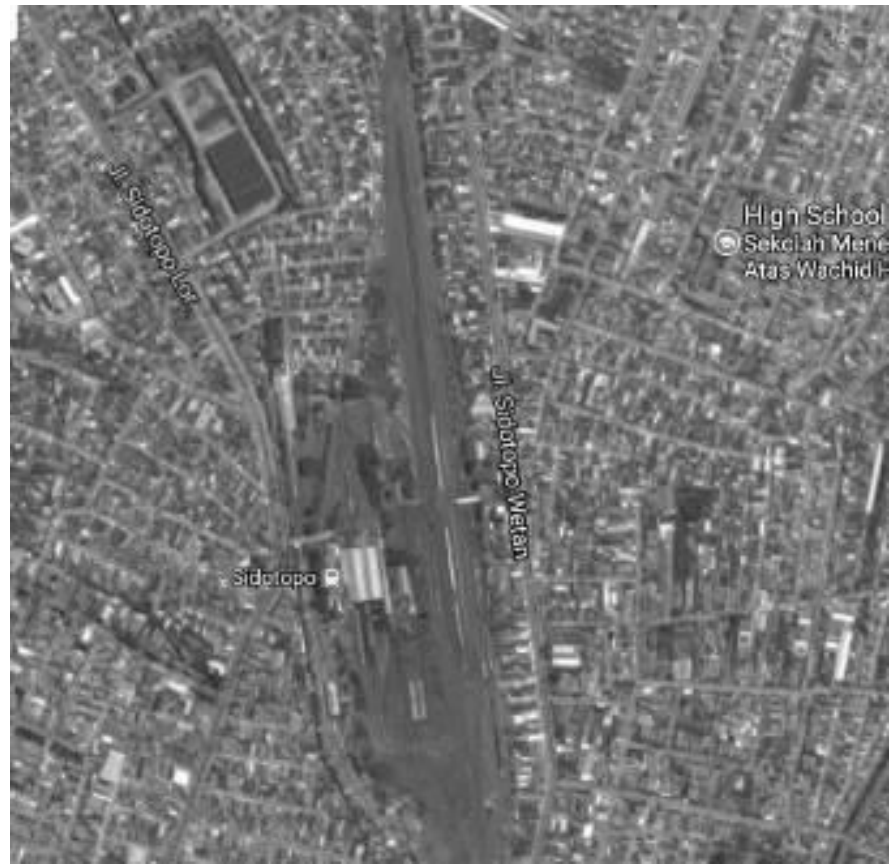

Gambar 1. Foto Udara Lokasi Tapak

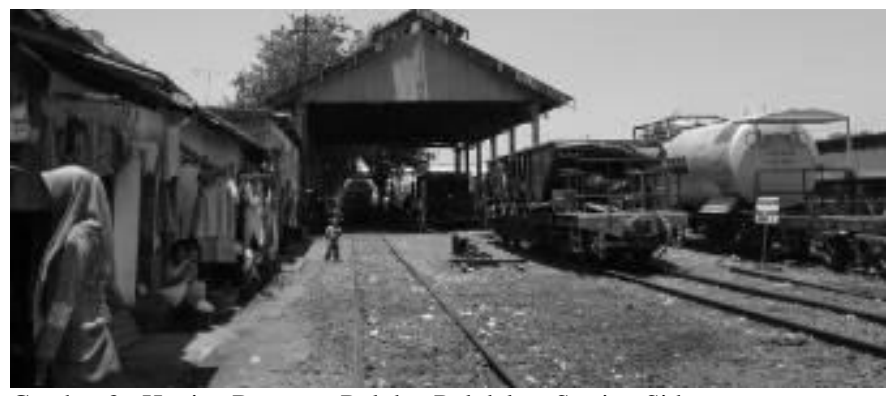

Gambar 2. Hunian Bantaran Rel dan Rel dalam Stasiun Sidotopo.

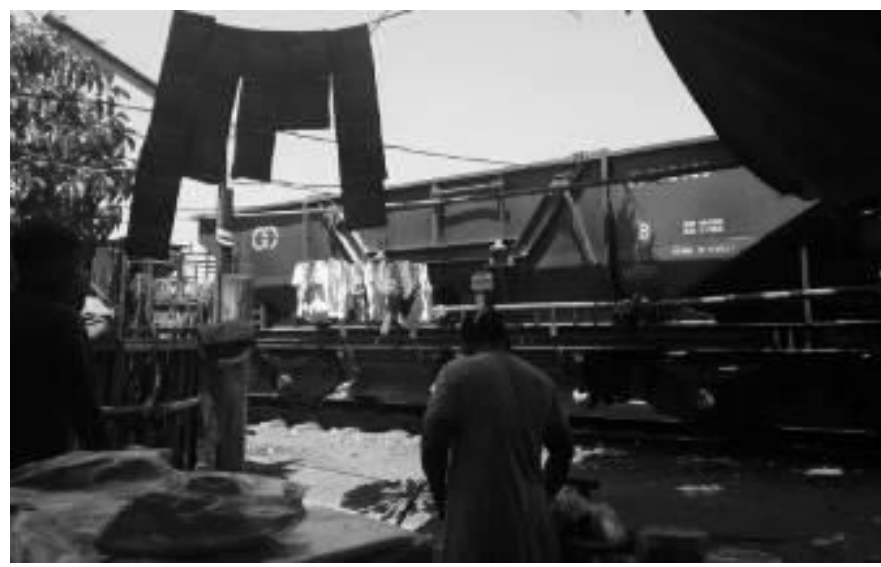

Gambar 3. Foto Keadaan Ruang Ternuka Dan Aktivitas Kereta Api. 
Masyarakat yang menjadi subjek atau pengguna di dalamnya, merupakan individu yang memiliki dan terbentuk sikapnya masing-masing, dari dirinya sendiri dan lingkungan sekitarnya. Karena hal tersebut diatas, sesuatu yang menyangkut tentang individu lebih banyak tidak dapat diseragamkan, namun sangat jelas dapat diarahkan. Dengan demikian, semua hal mestinya menjadi inklusif secara sosial maupun secara fisik.

Masyarakat yang tinggal di permukiman kumuh, permukiman informal maupun di hunian yang kurang memadai, mereka adalah orang-orang yang kekurangan. Mereka cenderung terasingkan secara spasial, sosial dan ekonomi, yang mana seharusnya mereka juga dapat menikmati apa yang orang lain nikmati [1]. Hal tersebut mendorong terwujudnya inklusifitas bagi masyarakat disadvantaged khususnya dalam hal permukiman. Acuan lainnya yaitu "where they already exist, to strengthen mechanisms for monitoring the impact of human settlement policies and programmes on the lives and work of disadvantaged persons in cities, including those in low-income areas and slums, and for enhancing vulnerable and disadvantaged persons' networks and other organizations active in the area" [2].

Terkait malasah permukiman, menurut UN Habitat saat ini 50\% dari 7 miliar penduduk dunia tinggal di kota. Hampir seluruh kota di dunia terutama di negara berkembang memiliki masalah permukiman yang juga kumuh, tidak hanya informal. Fenomena tersebut juga terjadi di Surabaya tepatnya pada permukiman yang berada di sepanjang rel kereta api Sidotopo. Rangcangan ini berada pada lahan seluas $\pm 27000 \mathrm{~m}$ persegi.

\section{METODA PERANCANGAN}

Pada tahap ini, kriteria desain yang dihasilkan dari pendekatan di awal digunakan untuk menyusun program desain. Transfer kriteria ke dalam programming menjadi bagian dari proses desain. Programming tersebut dihasilkan berdasarkan aktivitas pada ruang (events-based space) melalui pendekatan. Pengembangan program menjadi sebuah objek yang tidak dapat lepas dari tuntutan desain lingkungan sekitar. Sehingga di dalamnya juga mempertimbangkan keterkaitan antar aktivitas, objek, dan integrasi pada dua hal tersebut. Programming patterns yang terbentuk kemudian digunakan dalam pengembangan desain. Berdasarkan programming tersebut, metoda yang dipilih dalam desain ini menggunakan pattern-based design method. Metda ini memiliki framework dengan cara berpikir "the strength of a design process, as a uniqe activity is the combination of a thinking pattern that moves from exploration (divergen), to evaluation (convergent) to decision (selection) [3].

\section{A. Penggabungan Layer Area pada Ruang}

Pada masing-masing ruang, setiap aktivitas memiliki perlakuan yang berbeda. Pada desain ini, aktivitas dalam hunian dibuat beberapa layer bertumpuk (share space). Ruangan yang terbentuk dihasilkan berdasarkan ruangan terbesar dari gabungan aktivitas tersebut. Aktivitas yang dilakukan pada satu area tersebut ada yang dapat dilakukan pada waktu bersamaan, ada juga yang harus bergantian.

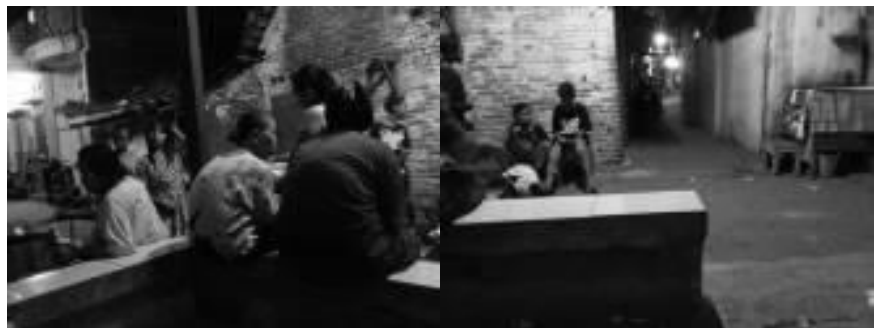

Gambar 4. Process Organization Chart, Design Guide

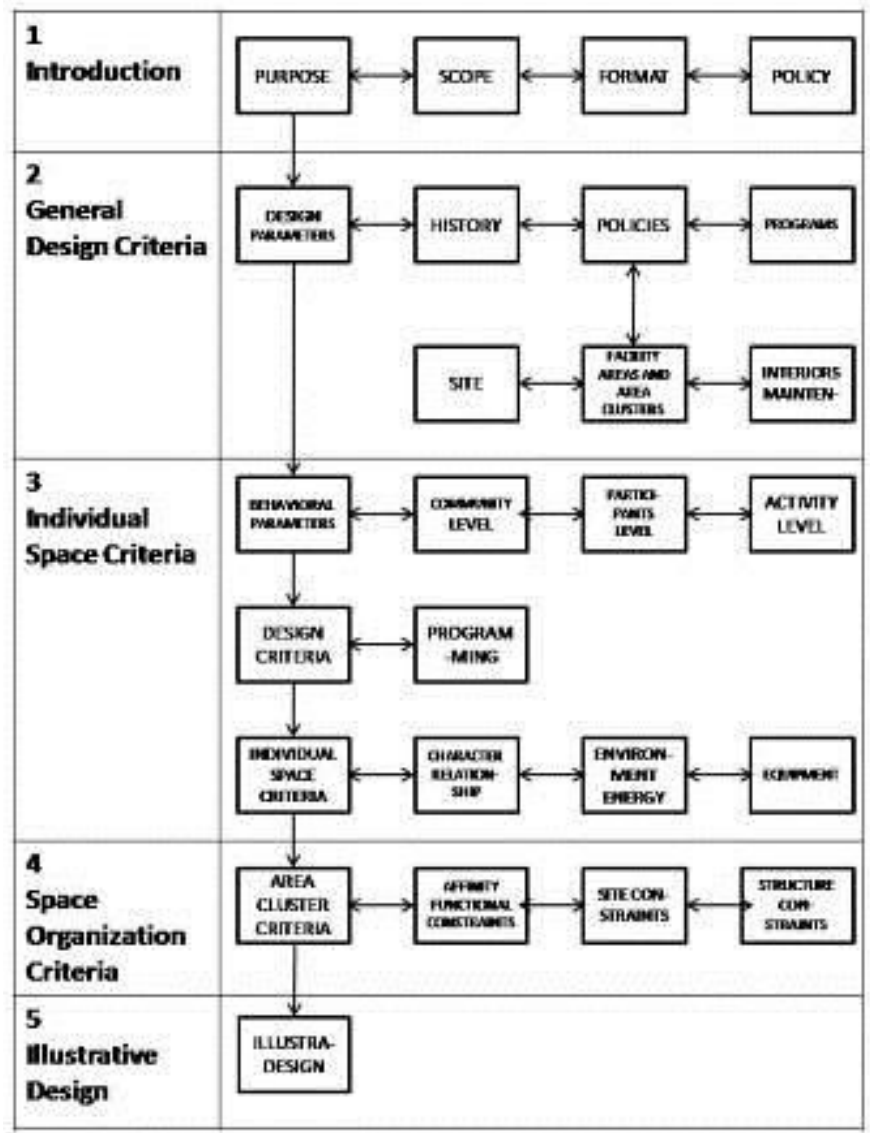

Gambar 4. Process Organization Chart, Design Guide

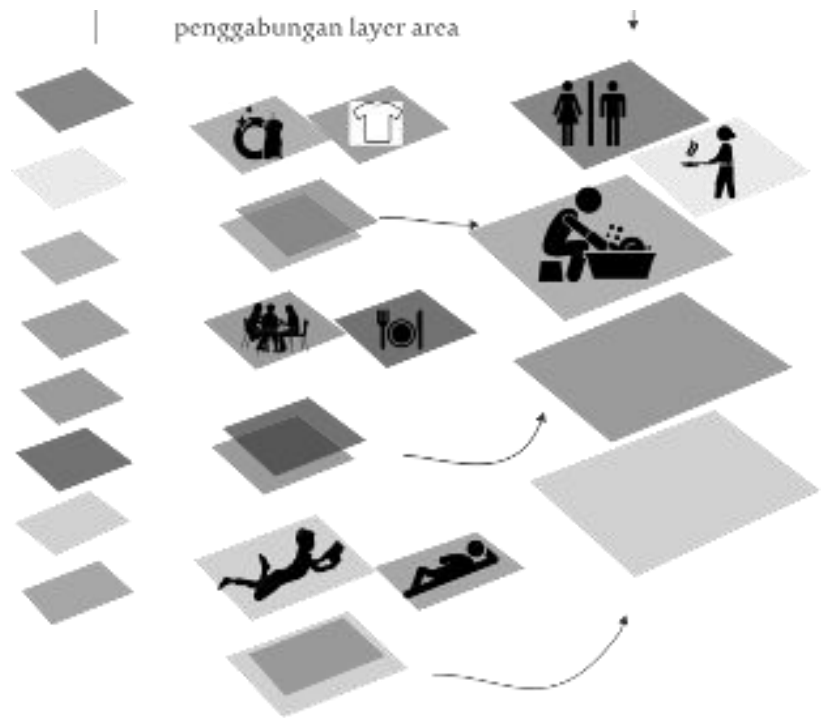

Gambar 5. Metoda Penggabungan Layer Aktivitas 


\section{B. Eksplorasi Pattern Hunian}

Hasil luasan ruang yang dibutuhkan untuk setiap tipe penghuni dari tahap sebelumnya kemudian dijadikan acuan untuk membentuk pola bangunan. Terjadi lima tahap dasar dalam membentuk tipe hunian, tahap pengembangan mulai dari nomor 6 diperlukan untuk hunian dengan luasan tapak lebih kecil. Pola tersebut terbentuk selain agar dapat menampung sejumlah program ruang, juga mendukung penggunaan energi alam utamanya untuk pemasukan cahaya matahari serta terbentuknya cross ventilation.

\section{Pembagian dan Desain tapak}

Tatanan hunian pada tapak didesain dengan membagi tapak menjadi beberapa bagian. Besaran setiap bagian pada tapak dibagi dengan acuan luasan terhadap kebutuhan luasan keterjangkauan, evakuasi dan kemudahan akses.

Tahap awal dilakukan dengan menentukan akses makro satu jalur dua arah. Jalur ini disediakan untuk akses evakuasi yang selanjutnya akan terhubung dengan jalur-jalur akses hunian.

Selanjutnya tapak dibagi menjadi empat bagian besar. Pembagian ini berdasarkan jumlah hunian yang ditampung dengan maksimal setiap bagian terdapat 120 hunian. Fasilitas ditentukan menjadi fasilitas pusat dan fasilitas menyebar yang terdapat pada masing-masing bagian tapak. Fasilitas pusat terdiri atas fasilitas kesehatan, PAUD, TK, taman baca dan taman terpusat. Sedangkan fasilitas yang tersebar di empat titik bagian merupakan fasilitas untuk menunjang aktivitas seharihari dengan kerapatan aktivitas tinggi dan waktu yang fleksibel. Fasilitas tersebut diantaranya mushola, balai warga, ruang terbuka / komunal dan jalur-jalur mikro yang aman dari kendaraan. Metoda yang digunakan dalam penataan ruang fasilitas adalah sama dengan penataan ruang pada hunian, yaitu menggunakan prinsip penggabungan layer aktivitas pada satu ruang.

Setelah pembagian tersebut, tahap selanjutnya yaitu persebaran tatanan tipe hunian. Pada tahap ini, empat bagian area hunian yang dibagi berdasarkan persebaran fasilitas, masih terbagi lagi menjadi beberapa klaster hunian. Hal tersebut disesuaikan berdasarkan faktor kepadatan, jarak kemudahan jangkauan hunian terhadap fasilitas maupun akses jalan. Persebaran tipe hunian dilakukan secara merata pada setiap klaster.

Sebagian besar orientasi hunian menghadap lingkungan dalam kecuali pada jenis hunian dengan fungsi tambahan sebagai tempat usaha, menghadap jalan. Sebagai optimalisasi penggunaan ruang untuk hunian, tatanan deret disusun setiap satu tipe dengan kompsisi tipe hunian seimbang antara persebaran satu kalster dengan klaster lainnya.
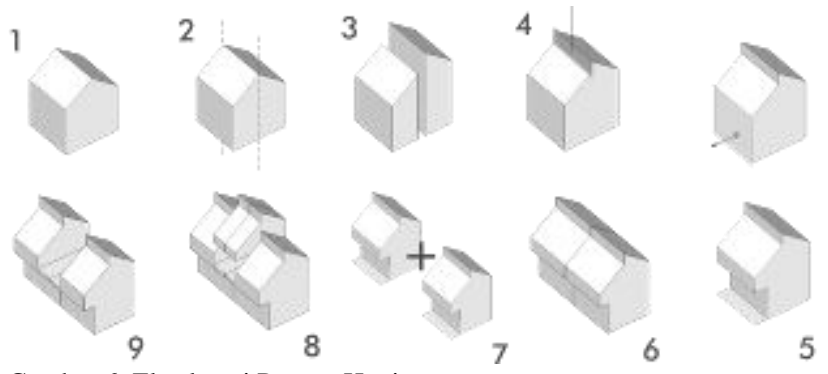

Gambar 6. Eksplorasi Pattern Hunian
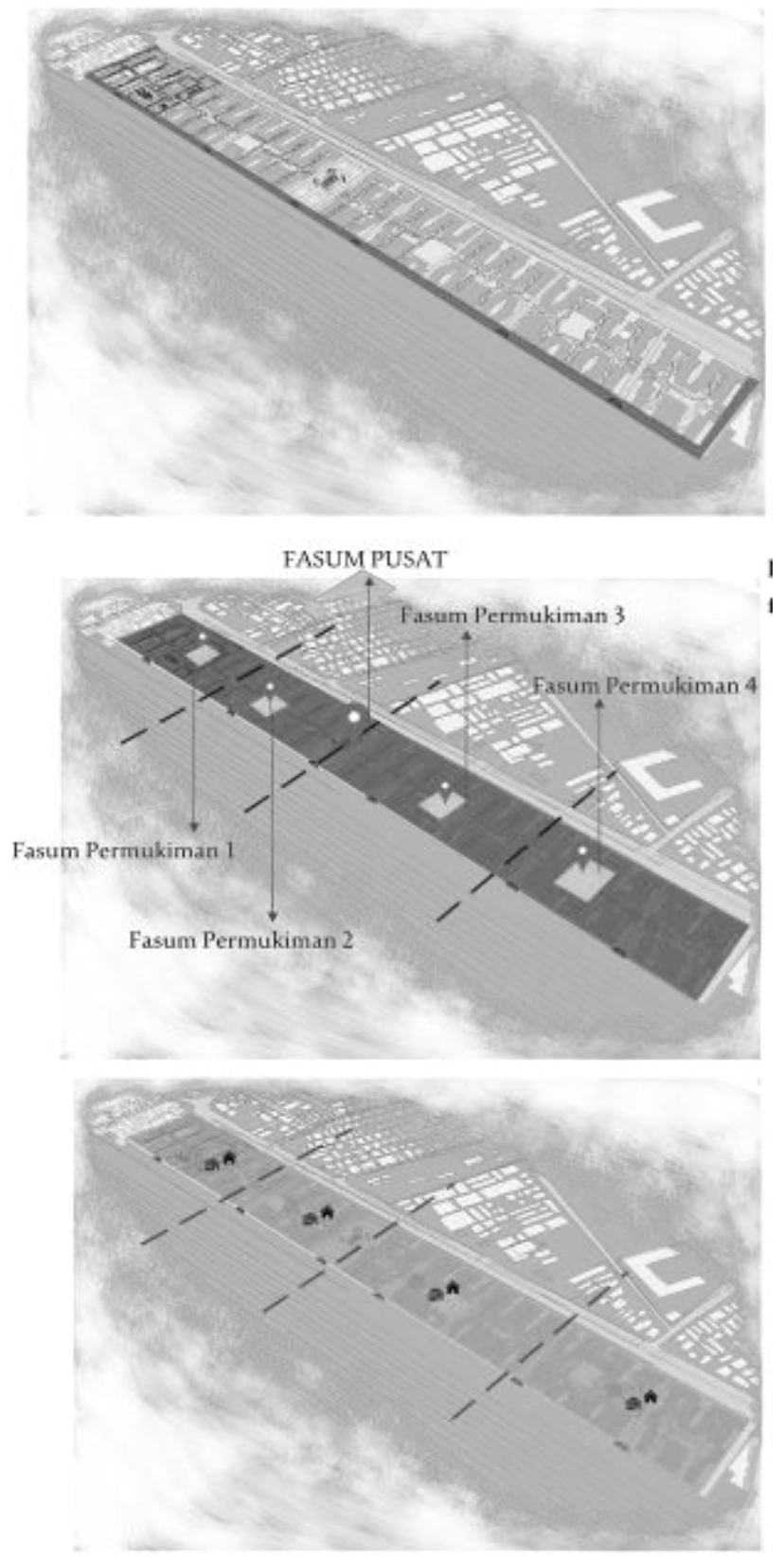

Gambar 7. Pembagian Area Hunian 


\section{HASIL PERANCANGAN}

\section{A. Detai Tipe Hunian}

Pada setiap detail hunian, terjadi penumpukan layer aktivitas pada ruangan yang terdapat sumber air. Aktivitas tersebut mencakup domestic activity, yaitu makan \& minum, bekerja, memasak, tidur, menerima tamu, bermain, belajar, menyimpan, MCK, mencuci, merapikan ruangan, istirahat /santai, dan memarkir [4]. Bagian yang tetap yaitu pada sirkulasi antara lantai 1 dan lantai 2, ruang kosong diantara sirkulasi tersebut dimanfaatkan sebagai ruang penyimpanan.

Pada setiap tipe hunian, ruangan dibuat berdasarkan jumlah dan kondisi (umur) penghuni. Luasannya diambil dan disesuaikan dengan optimasi ruang yang ada. Penumpukan layer aktivitas disesuaikan dengan kemiripan kebutuhan dan aktivitas. Penggunaan material berukuran custem sehingga fleksibel terhadap kebutuhannya.

Kondisi 1 dan kondisi 2 memperlihatkan keadaan yang berbeda. Area - area tersebut merupakan ruang yang mana terjadi penumpukan layer aktivitas yang bebeda. Penggabungan tersebut berdasarkan kemiripan aktivitas dan kebutuhan luasan program. Program aktivitas yang digabungkan diantaranya tidur dengan istirahat / bersantai, ruang penyimpanan dengan ruang tidur, almari makan dengan meja makan, sofa dengan tempat tidur dan area sirkulasi ketika fungsi lain tidak sedang berlangsung.

Penempatan perabot dan area - area permanen ditata sedemikian hingga mencapai fleksibilitas gerak dan efisiensi perpindahan. Selain itu juga menyesuaikan dengan kebutuhan pemasukan cahaya dan udara dari luar yang sebagian besar hanya terdapat pada area depan dan belakang sisi bangunan.

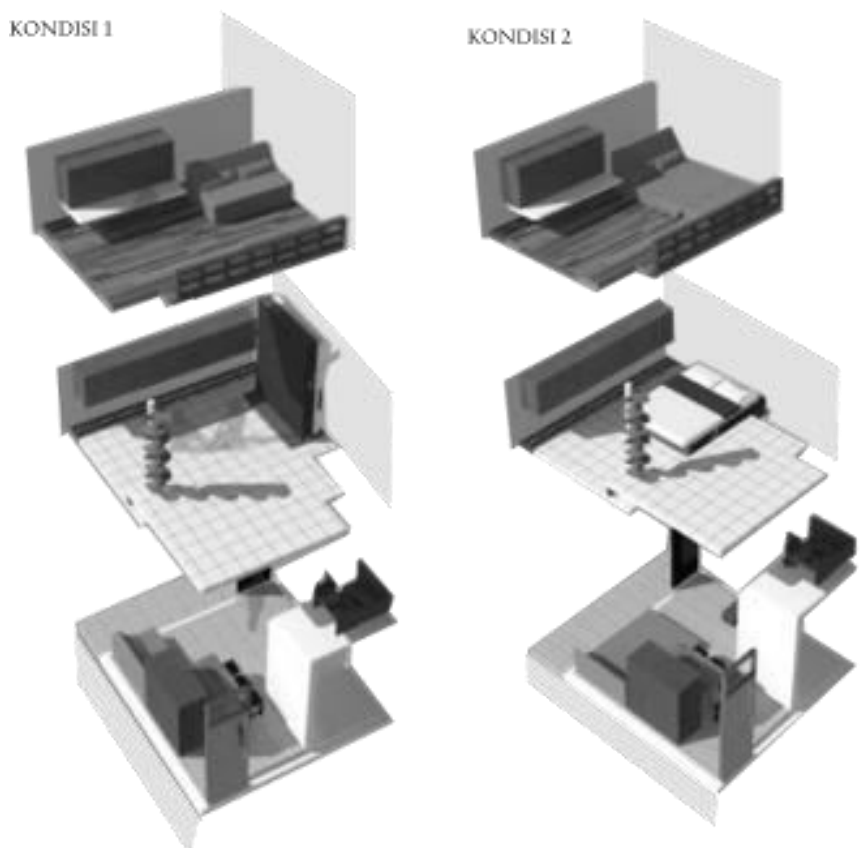

Gambar 10. Tipe 3. Detail Ruang, Fungsi, dan Perubahannya

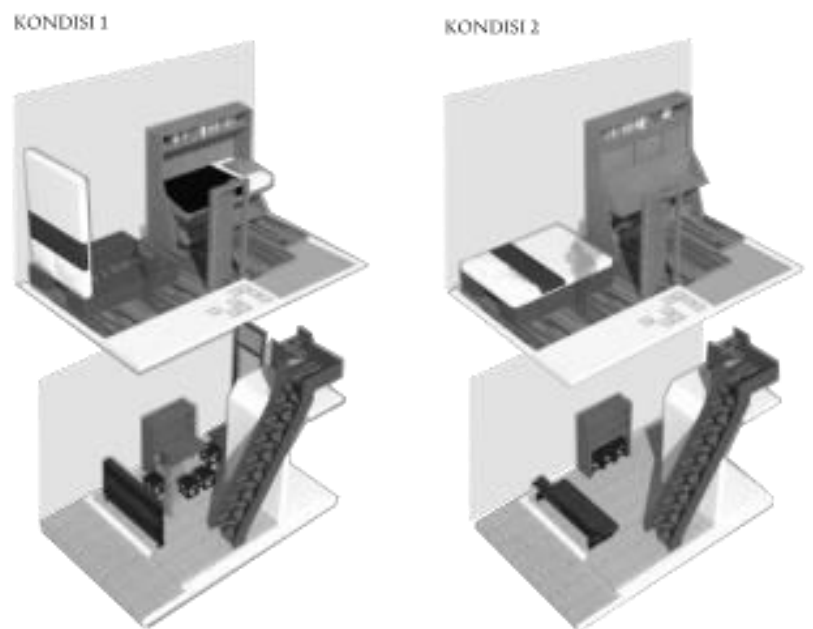

Gambar 8. Tipe 1. Detail Ruang, Fungsi, dan Perubahannya
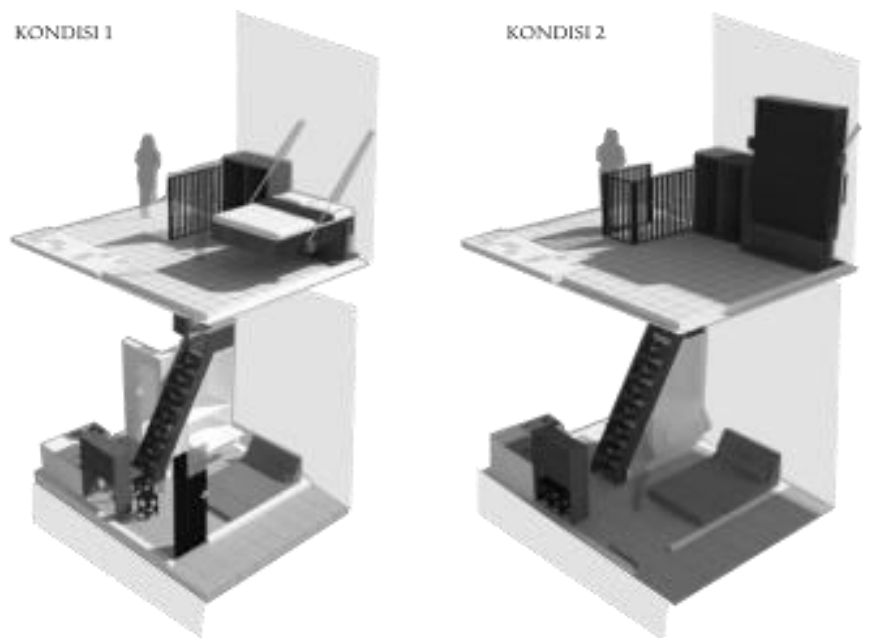

Gambar 9. Tipe 2. Detail Ruang, Fungsi, dan Perubahannya
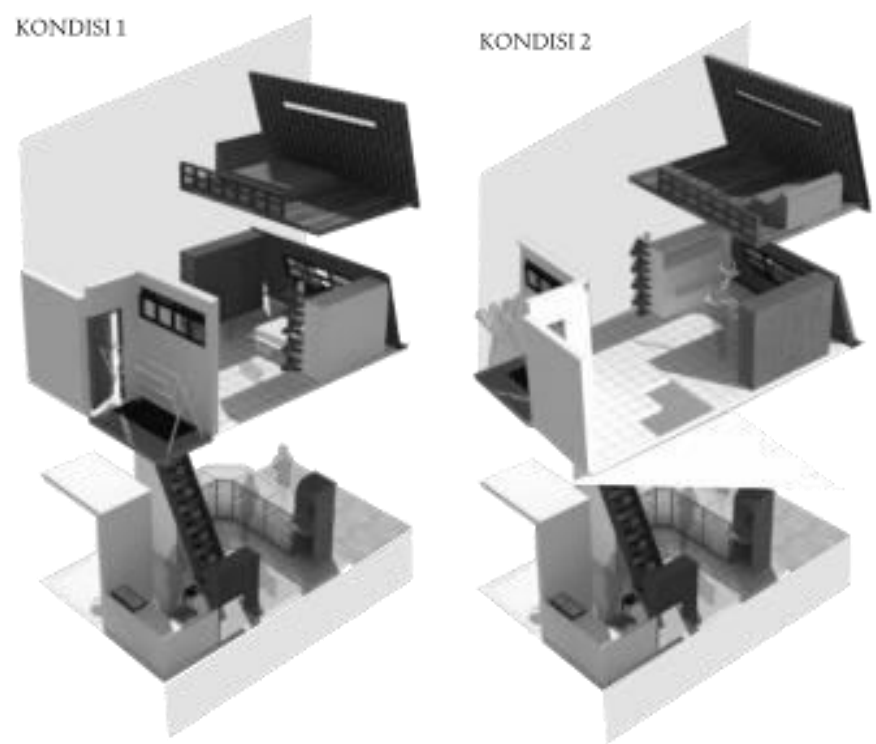

Gambar 11. Tipe 4. Detail Ruang, Fungsi, dan Perubahannya 


\section{B. Struktur}

Dengan konteks permukiman yang berada di kota, struktur baja lebih mudah didapatkan dan lebih rendah harga dibanding material lain dengan kekuatan yang hampir sama. Selain konteks tersebut pengerjaannya lebih cepat dan tidak terlalu memakan banyak ruang untuk penyusunan.

Konstruksi kolom dan balok dengan struktur utma baja dipilih dengan alasan kekuatannya yang tahan lama dan fleksibel untuk menentukan material pengisinya. Selain itu, material pengisi menggunakan batu bata ekspos dan beberapa bagian dibuat menjadi roster, yang mana mudah dihancurkan, dengan memiliki tujuan lain salah satunya yaitu evakuasi jika terjadi kebakaran pada bangunan lain.

\section{Tatanan Lingkungan Permukiman}

Tampak atas, tatanan sebagian hunian membentuk huruf $U$ atau memiliki rongga pada sisi yang berlawanan. Rongga tersebut difungsikan sebagai area bersama dan akses dari bagian belakang hunian. Jalur - jalur makro untuk akses kendaraan terlihat disiplin membagi area permukiman menjadi beberapa klaster. Jarak terkecil antar rumah yaitu 2,3 meter, jarak rata - rata 3 meter dan jarak terbesar yaitu 10 meter.

\section{KESIMPULAN}

Desain yang dihasilkan untuk menerapkan hunian inklusif dengan pemenuhan standar dan fasilitas kota dapat diterapkan pada lokasi dengan luasan terbatas dan kebutuhan penghuni yang banyak. Ketepatan dalam pemilihan dan penerapan penyelesaian masalah menjadi salah satu poin utama yang diterapkan. Pertama mengenai lingkungan hunian, tatanan hunian dan sirkulasi. Tiga komponen tersebut didesain dengan terpadu salah satunya hunian yang menyediakan dobel akses untuk kendaraan dan tanpa kendaraan. Kedua menyangkut hunian itu sendiri, terbentuk menjadi empat tipe hunian berdasarkan perbedaan penghuni pada setiap tipenya. Kemudian hal tersebut menjadikan luasan ruang yang dibutuhkan pada setiap hunian berbeda - beda. Dengan adanya luasan yang minim, sehingga penyelesaian utama pada hunian adalah dengan menggabungkan leyer aktivitas dalam hunian. Dengan demikian ruang - ruang terbuka menjadi lebih luas.

Dengan terakomodasinya masyarakat setempat akan kebutuhan hunian dan lingkungan yang lebih memadai, memiliki dampak pada perubahan pola kehidupan mereka. Hal yang cukup signifikan adalah mengenai luasan hunian pada setiap hunian, karena memiliki keseragaman sendiri. Sebaliknya dari dampak luasan hunian, tuntutan lingkungan yang sehat dan dapat mengakomodasi banyak macam kebutuhan dan kegiatan warga di dalamnya menjadi lebih layak.

Dari hasil penelitian tersebut menunjukkan bahwa sebaiknya masalah permukiman dan semacamnya yang belum dapat dijangkau oleh semua masyarakat dapat banyak terselesaikan. Apalagi dengan semakin maju teknlogi terutama untuk aplikasi struktur sehingga memudahkan pengerjaan.
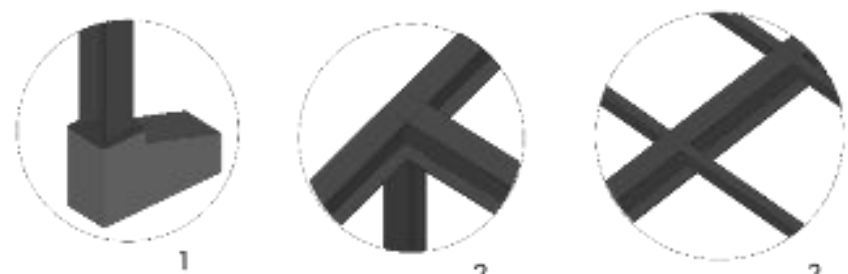

2

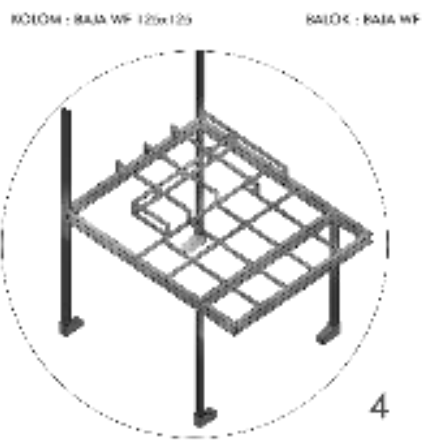

Gambar 12. Detail Struktur

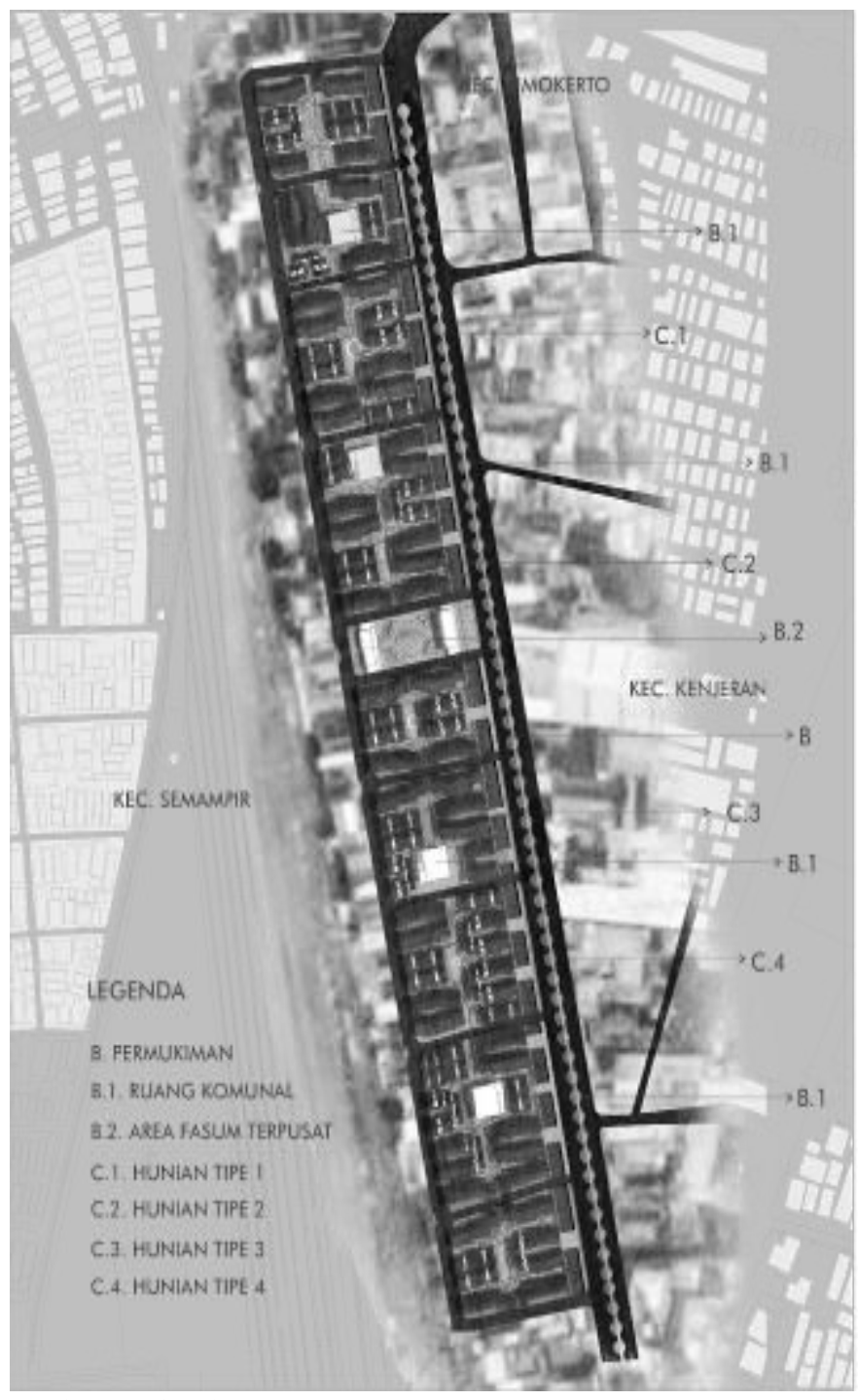

Gambar 13. Site Plan

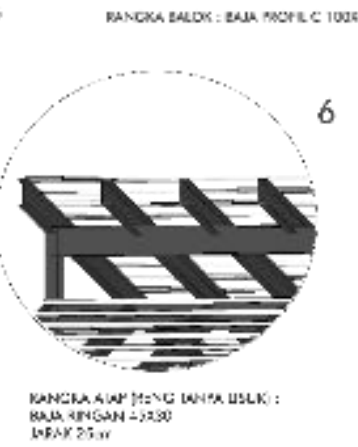

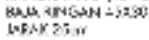




\section{UCAPAN TERIMA KASIH}

Penulis, Anggun Fresiani mengucapkan terima kasih kepada Direktorat Pendidikan Tinggi, Departemen Pendidikan dan Kebudayaan Republik Indonesia yang telah memberikan dukungan finansial melalui Beasiswa Bidik Misi tahun 20142018.

\section{DAFTAR PUSTAKA}

[1] U. Habitat and Nairobi, "Resolution 20/13: Housing as a component of the right to an adequate sttandard of living for persons who are vulnerable and disadvantaged." 2005.

[2] UN Departement of Economic and Social Affairs, "Goal 11:make cities and human settlements inclusive, safe, resilent and sustainable."

[3] P. D. Plowright, Revealing Architectural Design. New York: Universe Publishing, 2008.

[4] M. Faqih, "Domestic Activity and Culture Change," University of Newcastle, 2006. 